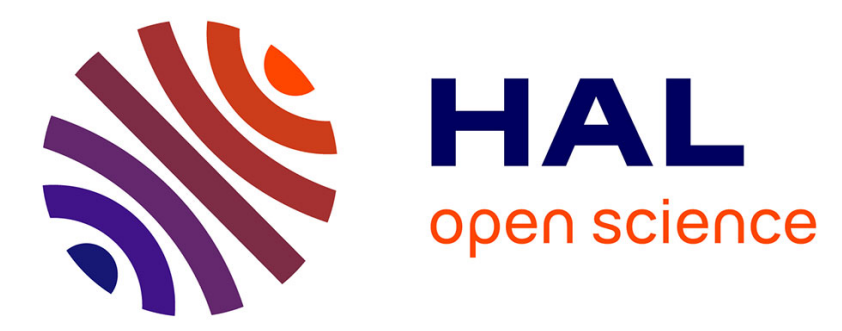

\title{
Workshop on Designing Interaction and Visualization for Mobile Applications (DIViM 2015)
}

Shah Rukh Humayoun, Achim Ebert, Steffen Hess, Gerrit van Der Veer

\section{To cite this version:}

Shah Rukh Humayoun, Achim Ebert, Steffen Hess, Gerrit van Der Veer. Workshop on Designing Interaction and Visualization for Mobile Applications (DIViM 2015). 15th Human-Computer Interaction (INTERACT), Sep 2015, Bamberg, Germany. pp.675-676, 10.1007/978-3-319-22723-8_97 . hal-01610790

\section{HAL Id: hal-01610790 \\ https://hal.inria.fr/hal-01610790}

Submitted on 5 Oct 2017

HAL is a multi-disciplinary open access archive for the deposit and dissemination of scientific research documents, whether they are published or not. The documents may come from teaching and research institutions in France or abroad, or from public or private research centers.
L'archive ouverte pluridisciplinaire HAL, est destinée au dépôt et à la diffusion de documents scientifiques de niveau recherche, publiés ou non, émanant des établissements d'enseignement et de recherche français ou étrangers, des laboratoires publics ou privés. 


\title{
Workshop on Designing Interaction and Visualization for Mobile Applications (DIViM 2015)
}

\author{
Shah Rukh Humayoun ${ }^{1}$, Achim Ebert ${ }^{1}$, Steffen Hess ${ }^{2}$, Gerrit van der Veer ${ }^{3}$ \\ ${ }^{1}$ Computer graphics and HCI Group, University of Kaiserslautern, Germany \\ ${ }^{2}$ Fraunhofer IESE, Kaiserslautern, Germany \\ ${ }^{3}$ Sino-European Usability Centre, Dalian Maritime University, Dalian, China \\ ${ }^{1}$ \{humayoun, ebert\}@cs.uni-kl.de, ${ }^{2}$ steffen.hess@iese.fraunhofer.de, \\ ${ }^{3}$ gerriteacm.org
}

\begin{abstract}
The DIViM 2015 workshop focuses on different issues and limitations regarding designing intuitive interaction and visualization for mobile applications and devices, as well as how to overcome these limits through novel approaches and techniques.
\end{abstract}

Keywords. Interaction Design; Visualization, Mobile App Development.

\section{$1 \quad$ Motivation and Objectives}

Current mobile applications (commonly abbreviated as mobile apps or just apps) are in many ways different from the conventional desktop applications due to factors like the usage of multi-touch gesture interaction, the availability of different sizes of devices, new operating systems, mobile access, the change of usage context in different circumstances, and so on.

The recent advances in mobile paradigm bring new challenges and open issues in developing intuitive and interactive mobile apps [1]. In this context, designing intuitive interaction and visualization plays an important role for many purposes, e.g., improved user experience and aesthetics. In addition, better interaction modes and suitable visual representations in mobile apps are critical for a successful execution of the users' required tasks [2]. However, this requires not only an intensive collaboration between the responsible parties - especially the interaction/UX designers, visualization and HCI experts - but also needs focusing on novel interaction and visualization approaches and techniques targeting this new mobile paradigm.

Inspired by the critical role of interaction design and visualization in the current mobile app development and the organizers' previous experience with the related fields (i.e., interaction designing, visualization, human experience, perception and multimodal input actions, and mobile apps), the workshop aims at creating awareness in the related communities to start focusing on novel methods, approaches, and techniques for utilizing the full power of interaction design and visualization in the current mobile app development at different levels, from showing the relevant information to enhancing user experience. 


\section{Workshop Details}

\section{Topics and Themes}

DIViM 2015 is dedicated to observations, concepts, approaches, techniques, and practices that allow understanding, facilitating, and increasing the awareness of the role of designing and implementing intuitive interactions and visualizations for mobile apps. In this context, topics of interest for paper submissions include, but are not limited to: novel interaction and visualization techniques and methods targeting current mobile apps and devices; frameworks and approaches for designing new interaction techniques and intuitive visualization; novel visual interactive techniques targeting mobile devices; scalability issues; context and usage issues; accessibility and usability issues; interaction and visualization for mobile smart watches; user-centric interaction/visualization; testing/evaluation; tools and environments to support the designing and building of interactive visualization; case studies and best practices.

\section{Target Audience}

The workshop targets at researchers and practitioners with a background in interaction design, UX design, visualization, HCI, or mobile app development. The workshop provides a platform for discussing issues and limitations regarding design and implementation of intuitive interaction modes and visualizations for mobile devices as well as how to overcome current limitations and user disaffection through novel approaches and techniques.

\section{Expected Outcomes}

The workshop aims at achieving the following outcomes:

- Consolidating research and practices related to interaction design and visualization design in the context of current mobile apps and devices;

- Establishing a platform for bringing the interested communities (such as interaction/UX designers, $\mathrm{HCI} /$ visualization experts, etc.) closer together to discuss how to make changes in the existing approaches and frameworks, as well as to examine novel methods for designing useful and intuitive interaction and visualization;

- Growing the body of knowledge related to interaction and visualization design for the current mobile environment and identifying challenges and future avenues for research relevant to both academia and industry;

- Providing a dedicated forum to the relevant communities for exchanging ideas and best practices; thus, foster collaboration between industry and academia.

\section{$3 \quad$ References}

1. Abolfazli, S., Sanaei, Z., Gani, A., Xia, F., and Yang, L. T. 2014. Review: Rich Mobile Applications: Genesis, taxonomy, and open issues. Network and Computer Applications, 40, 345-362.

2. Burigat, S. and Chittaro, L. 2013. On the effectiveness of Overview+Detail visualization on mobile devices. Personal Ubiquitous Computing, 17(2), 371-385. 